\title{
Maths concepts in teaching: procedural and conceptual knowledge
}

\author{
Caroline Long
}

\author{
Wits School of Education, University of the Witwatersrand \\ Email: longmc@educ.wits.ac.za
}

\section{Introduction}

In teaching a general course on mathematics for prospective teachers, ${ }^{1}$ I have found the theoretical distinction between conceptual knowledge and procedural knowledge (Hiebert \& Lefevre, 1986) a useful focus for teaching practice. The constructs provide a scaffold for the learning of mathematics by the students and for thinking about the teaching of mathematics in the school environment. These theoretical insights uncover in part the processes for acquiring knowledge and provide a tool for addressing problematic areas of learning. This distinction enables me the lecturer to analyse my teaching and the student to analyse their own learning and teaching, thereby contributing to the knowledge required for teaching.

While revisiting the much quoted work by Hiebert \& Lefevre (1986), for the purpose of deepening my understanding of conceptual knowledge, I was struck by the complexity of the constructs and therefore determined to address the view of algorithms as "just procedural", or the view that the understanding of concepts in the foundation phase must precede any scaffolding by procedures. $^{2}$

Hiebert and Lefevre (1986), following on the tradition of Scheffler (1965) and others, identified two kinds of knowledge, conceptual knowledge and procedural knowledge, that could be identified as distinct, but which were related in complex ways. The equivalent terms relational and instrumental understanding were used by Skemp (1976) to describe the similar theoretically distinct though practically linked constructs. He describes relational understanding as the ability to deduce specific rules and procedures from more general mathematical relations. Instrumental understanding describes the ability to apply a rule to the solution of a problem without understanding how it works. Subsequent to this, Kilpatrick, Swafford, and

\footnotetext{
${ }^{1}$ The students in this course have a varied mathematical background, some have mathematics up to grade 9 , but may not have "passed" the subject beyond Grade 7.

${ }^{2}$ Informal discussions with colleagues.
}

Findell (2001) included conceptual understanding and procedural fluency, similar in essence to the terms used by Hiebert and Lefevres (1986) as being two of five strands necessary for mathematical proficiency. ${ }^{3}$

While most mathematics educators would agree on both aspects of knowledge acquisition being important the "chicken and egg" debate about conceptual and procedural knowledge continues. Some reform movements, for example a Western Cape Departmental initiative from the late 1980s and early '90s discouraged teachers from teaching procedures and claimed that with sound conceptual understanding children would develop their own algorithms (James, 1995). Lack of insight into the pedagogical theories underpinning the reform movement caused confusion even among experienced teachers (op. cit.). Certainly the approach that encourages the development of own algorithms based on conceptual understanding has value and elicits varied responses, often insightful, from learners who have grasped the concept (Lampert, 2001; Ball, Lubienski \& Mewborn, 2001). This is in some cases the logical starting point for learning the more compacted algorithms. There is also evidence that a poor understanding on the part of teachers regarding the constructivist approach has led to learners having neither conceptual nor procedural knowledge (Schollar, 2004). The notion that there are stages in mathematical development and that learners typically go through a procedurally oriented phase before they can effectively integrate their conceptual knowledge is put forward by Davis, Gray, Simpson, Tall and Thomas (2000), who focus on high school mathematics.

In this paper I revisit the theoretical distinction and complex relationship between these two

\footnotetext{
${ }^{3}$ Three additional strands: strategic competence, adaptive reasoning, and productive disposition complement the above two constructs. Strategic competence is described as the "ability to formulate, represent and solve mathematical problems", while adaptive reasoning is described as "the capacity for logical thought, reflection, explanation and justification". Productive disposition refers to the "habitual inclination to see mathematics as sensible, useful, and worthwhile, coupled with a belief in diligence and one's own efficacy”.
} 
aspects of knowledge. I apply this distinction to the topic of number bases in a teacher education course. The complexity of the relationship raises some questions from both a theoretical and a practical perspective.

\section{Number bases}

The topic number bases is offered to all students in their second year of teacher education at the University of the Witwatersrand. The purpose for including working with different number bases in the course is so that students can experience learning a "new" number system and thereby reflect on the learning of our base-ten number system, which they learnt 12 years ago, and which they will be teaching in two to three years time. Two of the tasks expected of the students is converting between different bases and performing the basic operations of addition and subtraction. When teaching adding and subtracting using different bases the focus is initially on understanding the concept of place value and base. For example a base 5 number system would have groupings of five, as shown in Figure 1. The number system would be arranged according to place values ${ }^{4}$ based on powers of five as shown in Figure 2. make clear the theoretical distinctions made by Hiebert and Lefevre (1986), which inform my use of the terms conceptual knowledge and procedural knowledge, and show the complex relationship between them.

\section{Conceptual knowledge and procedural knowledge}

According to Hiebert and Lefevre (1986: 4) conceptual knowledge is achieved in two ways: by "the construction of relationships between pieces of information" or by the "creation of relationships between existing knowledge and new information that is just entering the system". An example of these two ways is given in Figure 3.

Hiebert and Lefevre make a secondary distinction between what they call primary level relationships and what they call the reflective level. The primary level refers to pieces of knowledge that are at the same level of abstraction. The reflective level refers to a higher level of abstraction from two pieces of knowledge that are initially conceived as separate pieces of knowledge. An example of working with different number bases is given in Figure 4.

Hiebert and Lefevre (1986) distinguish conceptual knowledge from procedural knowledge

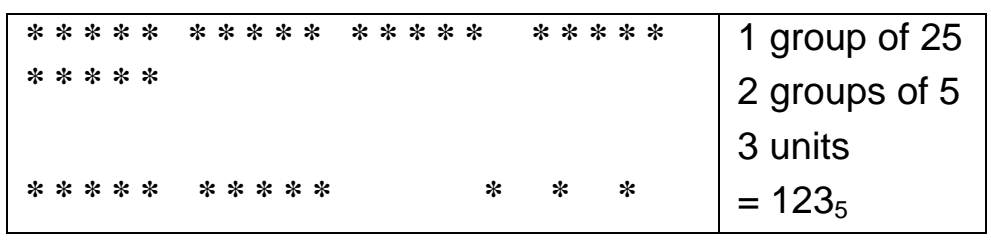

Figure 1. Grouping in Base 5

\begin{tabular}{|llll|}
\hline 125 & 25 & 5 & 1 \\
& or & & \\
$5^{3}$ & $5^{2}$ & $5^{1}$ & $5^{0}$ \\
\hline
\end{tabular}

Figure 2. Place value table
The focus moves from conceptual knowledge in Figure 1 to the procedural knowledge evident in Figure 2 and then to a focus on the acquisition of procedural knowledge, which includes the standard addition and subtraction algorithms. Before elaborating further on this topic, and discussing student responses to the tasks required of them I by saying that conceptual knowledge is identified by relationships between pieces of knowledge where-as procedural knowledge is identified as having a sequential nature.

For Hiebert and Lefevre procedural knowledge includes:

- knowing the formal language, or the "symbol representation system",
A student understands the relationship between place value and the procedure (algorithm) she learnt for doing multi-digit subtraction (two pieces of information are connected).

\section{A student connects the learning of addition in base 5 to addition in base 10 (new information is connected to existing knowledge)}

Figure 3. Conceptual knowledge: two ways of building knowledge relationships

${ }^{4}$ Different terminology is used initially to bring in students with little 


\section{Primary level}

When learners are first confronted with a number system with a different base, for example base 5, two facts may be presented to them, one is that the primary grouping is five, and the second is that they are only working with the symbols 1, 2, 3, 4 and zero. When drawing a number line in base 5 , these two bits of knowledge, the grouping of five (cardinal value) and the use of the symbols 1-4 and 0 to show the ordinal value are connected. This connection is made at a primary level where two pieces of information of equivalent conceptual density are connected.

\section{Reflective level}

At a reflective level the student, after grappling with different bases, base 5 , base 2, the hexadecimal system, may understand that the principles of working in any base are the same. ${ }^{1}$ The reflective level refers to a higher level of abstraction, which incorporates the essential principles connecting pieces of information initially conceived as separate.

Figure 4. Conceptual knowledge: two levels of relationship, primary and reflective.

- knowing algorithms and rules for completing tasks and procedures, and

- knowing strategies for solving problems.
Step 7: Trade 5 (groups of 5) for 1 group of 25 in the $5^{2}$, s column,

Step 8: Write left over 3 (groups of $5 \mathrm{~s}$ ) in the $5 \mathrm{~s}$ column. And so on...

Polya (1963), Mason, Burton and Stacey (1982) and others have very useful problem solving strategies which fall into the procedural knowledge category as defined by Hiebert and Lefevre (1986). In the textbook series Discovering Advanced Algebra (Key Curriculum Press, 2004), the section on matrices gives the student six steps to follow, which form the basis of an algorithm, for the related problems. These strategies, though underpinned by conceptual understanding, fall into the category procedural knowledge.

It should be clear from the above discussion that conceptual knowledge is intricately linked with procedures and algorithms. In fact, knowledge of procedures is nested in conceptual knowledge. In addition to the procedural fluency required in the above examples, understanding the many concepts embedded in the above procedures enables the student to use different methods, to remember the procedures more easily, and most importantly, to know whether the procedure had elicited a correct answer (Kilpatrick et al., 2001). 


\section{Application of the theory}

The conceptual knowledge/procedural knowledge distinction has been a useful construct enabling the students to reflect on their learning and to observe the nuances of teaching practices in the classroom. What happens on the part of the students who are trying to grasp the concept of working in a different base is an interesting question. It is not clear when individual students are working procedurally whether they are fully cognoscente of the link between place value and the base in which they are working. However, some are able to solve these problems using different strategies according to this evidence they have what Kilpatrick et al. term conceptual understanding. Other students focus on how to follow the procedure, in this case an addition or subtraction algorithm, with the conceptual focus taking back stage, and succeed in finding a solution to the problem. At the other end of the spectrum there are students who focus primarily on "how to" and for whom the conceptual links to the procedure remain elusive. This group differs from the previous group in that their conceptual knowledge is not back grounded; it is not apparent. These students might be able to apply the procedure to similar problems but change the context (in this case the number base) and they have to relearn the procedure. The first group gets straight to the concept, and can also work fluently with the procedure, but this is the group that has had access to mathematical knowledge and is able to process mathematically. The second group is slower at getting to the flexible understanding afforded by a grasp of the concept, which they only reach through the application of the procedures in a number of examples. An integration of the procedure with the concept appears to be the strongest approach with the procedure supplying the scaffolding for the concept and the concept underpinning the procedure. However, for the third group the links from the conceptual to the procedural and vice versa need to be made much more explicit.

On reflection staying at the iconic level with counters or dots on the board for an extended period is counter-productive, although this strategy does help to decompress the algorithm (Ball and Bass, 2000). In fact the algorithm incorporating the concept of place value and base becomes the stepping stone for conceptual understanding. The algorithm provided intellectual advantage beyond the first principles, in the same way that a frontend loader has mechanical advantage over a spade.

\section{The issues}

While I have found the distinction between conceptual and procedural knowledge useful, the pedagogical implications are far from clear. The foregoing discussion indicates that the following three issues are central to promoting a closer relationship between the procedural and the conceptual.

\section{Conceptual first or procedural first}

A foundation phase teacher educator using "good constructivist methodology" may say categorically that teaching the concept must come first and thereafter children are able to invent their own algorithms. In this case the executing of standard algorithms is perceived as indicating a lack of conceptual understanding and is aligned with rote learning, whereas the use of self-generated algorithms is perceived as conceptually rich. The view that the understanding of concepts before the learning of procedures makes some sense at a foundation phase level, though the research done by Rittleston-Johnson and Siegler (1998) indicates that even at foundation phase the conceptual/procedural distinction has a complex, sometimes iterative relationship.

Rittleston-Johnson and Siegler (1998: 109), after an extensive analysis and review of the literature on the relation between conceptual and procedural knowledge, conclude that there is a positive correlation between children's understanding of mathematical concepts and their ability to execute procedures. However, on the issue of "concepts preceding procedures" and "procedures preceding concepts" it is apparent that in some domains conceptual understanding precedes procedural competence, as for example in fraction addition.

The procedure to follow is to find a common denominator, then convert to equivalent fractions, then add ...

In other domains the order is reversed, for example counting. Children learn to count through nursery rhymes and to recognise the symbols before they develop the understanding of cardinal value. In still other domains, for example multidigit addition and subtraction, the order of acquisition is variable (Rittleston-Johnson and Siegler, 1998: 106). The general principles, which predict which come first, depend on timing and frequency of exposure. The more likely relation between conceptual and procedural knowledge, they concede, is an iterative one. However, for that to be tested there are a number of prerequisites that have to be put in place, one of which is careful task 


\section{Caroline Long}

analyses to identify the concepts that underlie a particular procedure.

\section{Procedural means rote}

Rote learning is defined as learning that is habitual repetition and devoid of conceptual understanding. The implication is that rote learning does not create a building block on which knowledge can be built, and does not provide a skill or knowledge that can be connected with any other skill or knowledge. The view that the executing of standard algorithms is devoid of conceptual understanding and therefore is aligned with rote learning is questionable. In this regard, the work of RittlestonJohnson and Siegler (1998) indicates that learning is a complex process in which the conceptual understanding underpinning the skill and the scaffolding function of the procedure both play a part in establishing proficiency.

\section{The undervaluing of algorithms}

The conflation of algorithms and procedures is another under-theorised area. The fluent execution of algorithms represents an aspect of procedural fluency. But algorithms in themselves cannot be said to be devoid of mathematical concepts. More to the point is that they represent compressed conceptual understanding; that is mathematical concepts that have been developed to a high level
The algorithm for converting between bases taught to engineering and computer science students seems on first encounter to be "pure magic". The answer arrives and as long as you know which end to begin recording you get it correct. The algorithm is on the left of Figure 6. The explanation and conceptual unpacking is on the right.

On first encounter the links to the place value concepts appear so compressed as to disappear into a black hole. But on analysis just so clever! In fact my students' response on seeing this was, "Why didn't you teach us that way?" My answer on reflection was, "Because you are teachers you must know the concepts underpinning the abstract procedures”. In fact some students did try this algorithm for conversions and made errors through not fully grasping the conceptual features inherent in this algorithm. But once understood this algorithm is the quickest method of converting between bases and circumvents going back to the basic conceptual building blocks each time. The counters and dots on the board support conceptual understanding at an iconic level. However, this attempt at scaffolding becomes very clumsy. Algorithms perform the function of an efficient technology, which free up byte space in the brain for focusing on the conceptual relationships.

\begin{tabular}{|c|c|c|c|c|c|c|c|c|c|}
\hline \multicolumn{10}{|c|}{ Convert $39_{10}$ to Base 2} \\
\hline 2 & 39 & & & $2^{5}$ & $2^{4}$ & $2^{3}$ & $2^{2}$ & $2^{1}$ & $2^{0}$ \\
\hline 2 & 19 & rem & 1 & 1 & 0 & 0 & & 1 & 1 \\
\hline 2 & 9 & rem & 1 & & & & & & \\
\hline 2 & 4 & rem & 1 & $19 \mathrm{~g}$ & $\mathrm{c}$ & with & & & \\
\hline \multirow[t]{2}{*}{2} & 2 & rem & 0 & 9 grc & s of & vith 1 & oup & 20 & \\
\hline & 1 & rem & 0 & $4 \operatorname{grc}$ & s of & vith 1 & oup & 4 ol & \\
\hline \multirow{2}{*}{\multicolumn{4}{|c|}{ Answer $39_{10}=100111_{2}$}} & \multicolumn{6}{|c|}{2 groups of 16 with 0 groups of 8 over } \\
\hline & & & & \multicolumn{6}{|c|}{1 group of 32 with 0 groups of 16 over } \\
\hline
\end{tabular}

Figure 6. Converting Base 10 to Base 2

of abstraction. Interesting research on the effective use of algorithms by students is the subject of a paper by Meira Hockman (2005). The answer at any level to the question of teaching algorithms and procedures is to analyse the concepts underpinning the component parts and thereby enable more complex mathematical thinking.

\section{Conclusion}

Kilpatrick et al. circumvent a dichotomy between the two strands by saying that "(i)n the domain of number, procedural fluency is especially needed to support conceptual understanding of place value...” (2001: 121). Algorithms are regarded by them as carefully developed procedures that are 
powerful and that form concepts in themselves. Hiebert and Lefevre (1986) conclude that it is the relationships between conceptual and procedural knowledge "that hold(s) the key" to improved mathematical understanding:

... although it is possible to consider procedures without concepts, it is not so easy to imagine conceptual knowledge that is not linked with some procedures. This is due, in part, to the fact that procedures translate conceptual knowledge into something observable. Without procedures to access and act on the knowledge we would not know it was there. (1986: 9)

My teaching focus has generally been on conceptual knowledge, without the procedural scaffolding. In some cases students have insisted on being told "how to" find a solution to a problem, circumventing the particular concept required to understand the problem. The students might be able to apply the procedure to similar problems but when the concept is changed which in this case could be changing from base 5 to base 2 , they are once more confronted with the need for understanding the concept. However, in some cases, algorithms support conceptual understanding and at a more complex level form the building blocks to understand the concepts. It is my pragmatic view in the design of this course that different aspects of the debate apply differently to particular mathematical concepts, to different stages of mathematical development and to different learning styles. I am also convinced that prospective teachers' access to these constructs and the related research allows them to make informed choices as to when to focus on different aspects of mathematical proficiency (Kilpatrick et al., 2001).

However, the warning inherent in the theoretical analyses mentioned above is that it is not always possible to distinguish concepts from procedures because understanding and doing are connected in complex ways. Brodie (2004: 72-73) elaborates on the complex relationship between mathematical knowledge, practices and mathematical teaching practices. For the purposes of this course, Maths Concepts in Teaching, the distinction between conceptual knowledge and procedural knowledge performs a scaffolding function which is sufficiently clear to be cognitively accessible to the students and provides a starting point for a careful conceptual analysis of what concepts and skills underpin important mathematical ideas. The scaffolding function also enables the detection of students who rely solely on procedural knowledge in some aspect of mathematics, for example multi-digit multiplication, and for whom a deeper conceptual understanding is necessary. Further conceptual analysis of mathematical topics that includes not only the concepts and the skills required by students, but includes the conceptual and historical evolution of specific mathematics topics is the focus of further research (Long, in process).

\section{Acknowledgement}

This paper was presented at the ICMI Regional Congress, University of the Witwatersrand, June, 2005. I am grateful to Karin Brodie and Nick Taylor for helpful comments in the initial conceptualising of this paper. Thanks also to the Pythagoras reviewers for insightful comments on the paper.

\section{References}

Ball, D. \& Bass, H. (2000). Interweaving context and pedagogy in teaching and learning to teach: Knowing and using mathematics. In J. Boaler (Ed.), Multiple perspectives on teaching and learning mathematics (pp. 83-104). Westport, CT: Ablex.

Ball, D.L., Lubienski, S.T., \& Mewborn, D.S. (2001). Research on teaching mathematics: The unsolved problem of teachers' mathematical knowledge. In V. Richardson (Ed.), Handbook of research on teaching (4th edition) (pp. 433456). New York: MacMillan.

Brodie, K. (2004). Re-thinking teachers' mathematical knowledge: A focus on thinking practices, Perspectives in Education, 22(1), 6580.

Davis, G. Gray, E. Simpson, A., Tall, D. \& Thomas, M. (2000). What is the object of the encapsulation of a process? Journal of Mathematical Behaviour 18(2), 223-241.

Hiebert, J. \& Lefevre, P. (1986). Conceptual and Procedural Knowledge in Mathematics: An Introductory Analysis. In J. Hiebert (Ed.), Conceptual and Procedural Knowledge: The Case of Mathematics (pp. 1-27). Hillsdale, NJ: Erlbaum.

Hockman, M. (2005). Dynamic geometry: an agent for the reunification of algebra and geometry, Pythagoras 61, 31-45.

James, C. (1995). A small-scale investigation into foundation phase teachers' access to the theoretical underpinnings of the new mathematics curriculum. Unpublished masters' thesis, University of Cape Town. 


\section{Caroline Long}

Key Curriculum Press (2004). Discovering Advanced Algebra. Emeryville: Key Curriculum Press.

Kilpatrick, J., Swafford, J. \& Findell, B. (Eds.) (2001). Adding it up: Helping Children learn Mathematics. Washington DC: National Academy Press.

Lampert, M. (2001). Teaching Problems and the Problems of Teaching. New Haven: Yale University Press.

Long, C. (2003). Mathematics Knowledge for Teaching: How do we recognise this? In S. Jaffer \& L. Burgess (Eds.), 9th Annual Congress of the Association for Mathematics Education of South Africa (AMESA) (pp. 194204). Cape Town.

Long, C. (in press). The conceptual and historical development of ratio.
Mason, J., Burton, L. \& Stacey, K. (1982). Thinking Mathematically. London: AddisonWesley.

Polya, G. (1963). How to solve it. Princeton: Princeton Press.

Rittleston-Johnson, B. \& Siegler, R.S. (1998). The relation between conceptual and procedural knowledge in learning mathematics: A review. In C. Donlan (Ed.), The development of mathematical skills (pp. 75-110). Hove, UK: Psychology Press.

Schollar, E. (2004). Primary Mathematics Research Project. Johannesburg: Eric Schollar and Associates.

Scheffler, I. (1965). The Conditions of Knowledge. Glenview, Illinois: Scott, Foresman and Company.

Skemp, R. (1976). Relational understanding and instrumental understanding. Mathematics Teaching 77, 20-26.

"Difficulties increase

the nearer we get to

the goal."

Johann Wolfgang

von Goethe 